\section{Therapiehoffnung am seidenen Faden}

\author{
Raue, kratzige Bekleidung kann bei Kindern die Symptomatik einer \\ atopischen Dermatitis zusätzlich verschlimmern. Auf der Suche \\ nach einer Faser mit geringem irritativen Potenzial überprüften \\ italienische Forscher jetzt einen speziell verarbeiteten Seidenstoff.
}

$\mathrm{D}$ ermatologen der Universität Bologna dokumentierten die Daten von 46 Kindern im Durchschnittsalter von 2 Jahren mit atopischem Ekzem in der akuten Krankheitsphase. Die 31 Kinder der Gruppe A erhielten spezielle Seidenkleidung, die sie eine Woche lang ausschließlich tragen sollten. Die verwendete Seide enthielt kein Sericin - ein potenziell allergenes Protein der Seidenraupe -, war besonders glatt verarbeitet und zusätzlich mit einer antimikrobiellen Beschichtung versehen worden. Die Kontrollgruppe (Gruppe B) umfasste 15 Kinder; sie wurden mit Baumwollstoffen bekleidet. Nur Feuch-

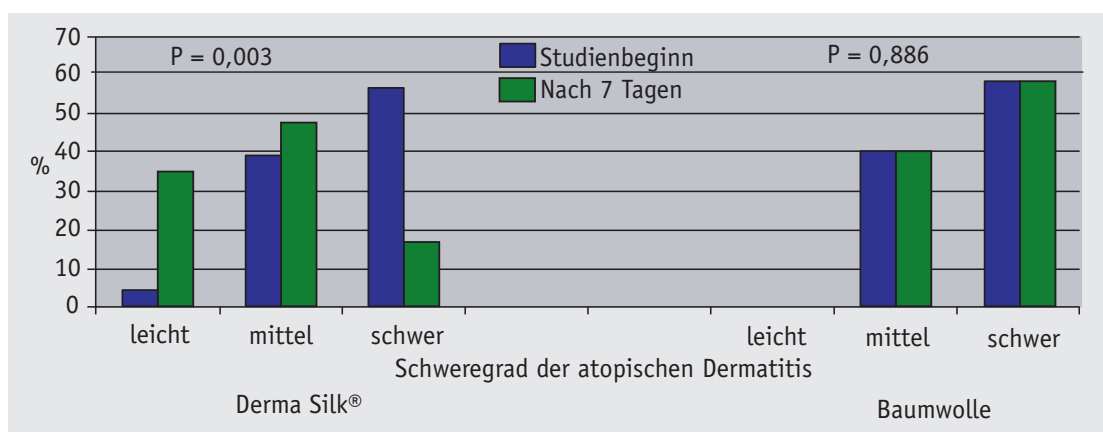

Veränderung des Anteils von Kindern mit milder, moderater und schwerer atopischer Dermatitis nach einwöchigem Tragen von Bekleidung aus DermaSilk ${ }^{\circledR}$ oder Baumwolle tigkeitscremes oder -emulsionen waren zur Behandlung erlaubt.

Bei der Untersuchung nach 7 Tagen hatten lediglich 23 Kinder der Verumgruppe die Kleidung vorschriftsmäßig getragen, die Befunde der übrigen acht Kinder wurden nicht ausgewertet: Der SCORAD-Index hatte sich in Gruppe $A$ von 43 signifikant auf 30 verbessert ( $p=0,003)$, in Gruppe B war er mit einer Änderung von $47 \mathrm{zu} 46$ nahezu gleich geblieben.

Zusätzlich verglichen die Ärzte die Symptome an seidenbedeckten Hautarealen und nicht bekleideter Haut bei 18 Kindern der Gruppe A. Es zeigte sich im SCORAD-Index eine signifikante Verbesserung der bedeckten Läsionen von 32 auf 18,6 ( $\mathrm{p}=0,001)$. Die SCORAD-Werte der unbedeckten Haut sanken nicht signifikant von 31 auf 26.

Fazit: Die verwendeten Stoffe aus speziell angefertigter, gewobener Seide lindern offensichtlich die Symptome bei Kindern mit atopischen Ekzem. mha

Ricci G et al. Clinical effectiveness of a silk fabric in the treatment of atopic dermatitis. Br J Dermatol 2004; 150: 127-31

\title{
Borretschöl hilft nicht bei Neurodermitis
}

\section{Eine Hypothese zur Genese des atopischen Ekzems geht davon aus, dass es den Patienten an bestimmten Fettsäuren, speziell der Fähigkeit zur Bildung der $\gamma$-Linolensäure, mangelt. Demnach sollte die Substitution dieser Substanz die Symptome von Neurodermitis- Patienten beheben.}

B orretschöl enthält einen hohen Anteil an $\gamma$-Linolensäure, einer essenziellen Fettsäure, die bei Patienten mit atopischem Ekzem offenbar ungenügend zur Verfügung steht, um in antiinflammatorische Mediatoren wie Prostaglandin E umgewandelt zu werden. Vor diesem Hintergrund überprüften englische Forscher die Wirkung einer Substitution mit Borretschöl-Kapseln in einer sehr hohen, bisher nicht untersuchten Dosierung.

Über einen Zeitraum von 12 Wochen erhielten 45 Erwachsene, die an einem atopischen Ekzem litten, zweimal täglich vier Kapseln mit Borretschöl (insgesamt $920 \mathrm{mg} \gamma$-Linolensäure), 40 symptomatische Kinder erhielten zweimal täglich zwei Kapseln. In der Plazebogruppe waren 26 Erwachsene und 29 Kinder. Während des Studienzeitraums war konventionelle Therapie erlaubt, auch topische Glukokortikoide durften zur Anwendung kommen. Die Wirksamkeit des Präparates wurde mittels des SASSAD-Scores (Six Areas, Six Signs, Atopic Dermatitis), der Grad der
Symptome mittels einer visuellen Analogskala und die Verträglichkeit mittels einer Vierpunktskala erfasst.

Nach 12 Wochen Therapie kamen erstaunliche Ergebnisse zu Tage: Der SASSAD-Score fiel in der Verumgruppe von 30 auf 27, in der Plazebogruppe von 28 auf 23. Die Symptome verbesserten sich geringfügig mehr in der Plazebogruppe, die Verträglichkeit war in beiden Gruppen gut. Der Bedarf an topischen Glukokortikoiden blieb während des Studienzeitraumes unverändert.

Fazit: Diese Studie widerlegt jegliche Effektivität von Borretschöl bei atopischem Ekzem.

$o j$

Takwale A et al.: Efficacy and tolerability of borage oil in adults and children with atopic eczema: randomised, double blind, placebo controlled, parallel group trial. BMJ 2003; 327: 1385-8 